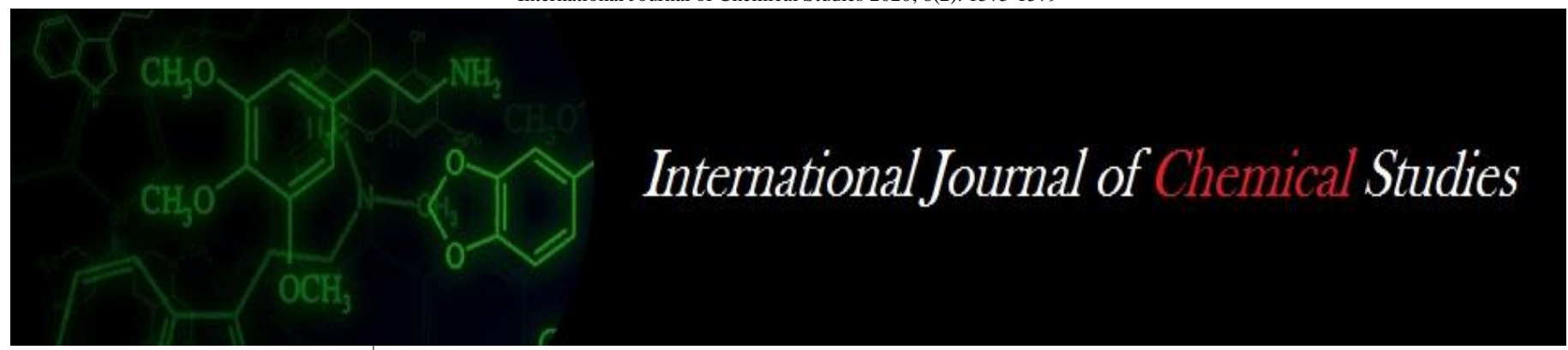

P-ISSN: 2349-8528

E-ISSN: 2321-4902

www.chemijournal.com

IJCS 2020; 8(2): 1575-1579

(C) 2020 IJCS

Received: 17-01-2020

Accepted: 20-02-2020

Achyutananda Das

SOA University, Bhubaneswar,

Odisha, India

MK Ghosal

Professor, Department of Farm

Machinery and Power, Odisha

University of Agriculture and

Technology, Bhubaneswar,

Odisha, India

\section{DK Das}

Former Professor \& Head, Department of Farm Machinery and Power, Odisha University of Agriculture and Technology, Bhubaneswar, Odisha, India
Corresponding Author: MK Ghosal

Professor, Department of Farm Machinery and Power, Odisha University of Agriculture and Technology, Bhubaneswar, Odisha, India

\section{Development and performance studies of electronic wheel slip control device for two wheel drive agricultural tractor}

\author{
Achyutananda Das, MK Ghosal and DK Das
}

DOI: https://doi.org/10.22271/chemi.2020.v8.i2x.8986

\begin{abstract}
An electronic slip control and measuring device for two-wheel drive (2WD) agricultural tractors was developed for online measurement of wheel slip and to study its performance under varying field conditions. The field trials were conducted in the Central Farm of OUAT, Bhubaneswar, Odisha, India during 2015-16. The measuring efficiency and maximum error of the developed slip meter were found above $99 \%$ and $002 \%$ respectively. As compared to the existing draft control system (DCS), the developed slip control system showed significant improvement in fuel economy i.e. in the range of 25$32 \%$ in ploughing, $15-32 \%$ in harrowing and $6-25 \%$ in tilling and the improvement in field capacity were also in the range of $15-20 \%$ in ploughing, $9-37 \%$ in harrowing and $10-24 \%$ in tilling as compared to DCS.
\end{abstract}

Keywords: Agricultural tractor, electronics in tractor, wheel slip control device, tractive efficiency

\section{Introduction}

The Steep increase in the price of petroleum fuels has adversely affected the management and economy of vehicular operations. Consistent efforts have been made to maximize the fuel efficiency in all type of vehicles. In current scenario, the preference of vehicles is mainly based on their fuel efficiency. In agricultural sector, fuel consumption is a major concern as $35 \%$ of the operational cost is attributed towards the cost of fuel consumption (Tiwari et al. 2009) ${ }^{[1]}$. Fuel efficiency is maximized by optimising the tractive efficiency which can be achieved by matching the tractor with suitable implement and load for a given tractor. In the case of 2WD tractors, as predicted by Sharma and Pandey $1998^{[2]}$, slip has a significant role in improving the tractive performance. Tractors function at peak efficiency if their slip is maintained within an optimum range depending on the type of soil (Raheman and Jha, 2007) ${ }^{[3]}$. But this is not possible for the current makes and model of $2 \mathrm{WD}$ tractors as they are controlled by the conventional draft control system (DCS). In a practical situation, it is observed that for achieving the maximum efficiency, slip control system is highly preferable as compared to draft control system (Kumar and Pandey 2009) ${ }^{[5]}$. Many researchers have come to the conclusion that the present draft control system possesses disadvantages for the driver as it is difficult and impracticable to make frequent adjustment of depth control levers which results in poor efficiency of tractive system (Pranav and Pandey, 2008) ${ }^{[4]}$. This necessitates a control system which will continuously measure the slip to help the driver for managing wheel slip within a given range under varying soil and field conditions. The slippage of tractor wheels drastically affects the tractive efficiency which needs to be enhanced by regulating and optimizing the slippage as slip is a very important parameter and plays a significant role in operating the tractor. By suitable regulation and management of slip within certain optimum range during field use, tractive efficiency can be maximized. Improvement of fuel efficiency and field capacity could also be considerably achieved by managing slip in the optimum range (Behera 1989) ${ }^{[6]}$. The most desirable method for improving tractive efficiency could be by controlling and maintaining the slip within optimum range by changing the depth of operations. It is required that a system continuously measures and provides input to the driver to maintain slip within an optimum range throughout the operations. As soon as the slip deviates beyond the range, the operator should notice the indications on the slip 
meter and bring back the slip to specified range by operating the depth control lever. The slip control provides faster response than the existing draft control method. This system would overrun the draft control mechanism for effective and efficient operations. Considering the above problems for the efficient operation of tractor for agricultural operations, an attempt is made through the present study with the objectives of developing an online slip sensing and measurement device for $2 \mathrm{WD}$ tractors to provide guidance to the driver for maintaining slip within specified limit for achieving maximum efficiency and its performance evaluation for acceptance among the tractor manufacturers.

\section{Materials and Methods}

The electronic slip meter was fabricated in the workshop of M/S John Deere, C/O Kishan Motors, Bhubaneswar. The field trials were undertaken in the Central Farm OUAT, Bhubaneswar during 2015-16. The type of soil in the field is sandy loam.

\section{Development of Slip Meter}

The design of slip meter is based on the calculation methodology. As per the definition, slip is the percentage difference between the theoretical and actual speed/velocity of a moving vehicle. The distance was calculated by counting the number of revolutions of the wheel and multiplying the same by its circumference. In order to calculate slip, there is a requirement for determining the theoretical and actual velocity. While, the theoretical velocity is obtained by counting the number of revolution per second multiplied with the circumference of drive wheel, the actual velocity is the product of number of revolution per second and the circumference of the front wheel. After determining the theoretical and actual velocity, the slip can be easily computed with the algorithm.

$\mathrm{S}=(1-\mathrm{Va} / \mathrm{Vt}) \times 100 ;$ where $\mathrm{S}=\mathrm{Slip}$ in $\%$ age; $\mathrm{Va}=$ Actual velocity; $\mathrm{Vt}=$ Theoretical velocity

\section{Development process of encoder}

The encoder is basically a transducer which converts the physical changes into digital information in the form of digital signal so that the physical changes can be computed by the computer or microcontroller systems. For counting revolutions of wheels, the rotary motion needs to be transformed into digital information. One complete revolution of wheel is equal to the angular motion of 360 degrees. For the particular design of encoder for slip measurement, this 360 degree provides 9 pulses by a special sensing arrangement by generating the same at 40-degrees interval. To achieve the same, an iron ring was specially fabricated and fixed to rotate along with the axle of the tractor wheel. Provision was made with 9 projections of iron strip in the fabricated wheel at 40-degree angular distance to provide 9 pulses by the magnetic pick up encoder system. The pulses are fed to the microcontroller to count one revolution for receiving every 9 pulses from the encoders system with one complete rotation. Hence with one complete revolution, the tractor moves a distance of one circumference length of its wheel $\mathrm{i}$ e $2 \pi \mathrm{r}$ meters where $\mathrm{r}$ is the radius of the wheel in meter. After the distance measurement, velocity was found out. The rear and front wheels provide the theoretical and actual velocity respectively. The sensor work in the principle of Faraday's law of electromagnetic induction. The magnetic pick up sensor contains a permanent magnet, a pole piece and sensing coil kept inside a cylindrical enclosure. As the sensors are fixed to sense the magnetic target at the interval of 40 degree, as per the Faraday's law, a pulse is generated by the sensor when the target passes in close proximity of the sensor. The metallic ring was fixed to the rim and rotates along the rotation of wheel, whereas the sensor was installed on to the fixed part, near the wheel as shown in Fig. 1. When the wheel begins to rotate, the target cut the magnetic field and generates a signal in the output of the magnetic pick up sensor. The distance or air gap between the target and the magnetic pickup is kept between 0.5 to $2 \mathrm{~mm}$ as per the manufacturers' specifications. The output wave form of the magnetic sensor is $60 \mathrm{f}=\mathrm{RE}$ where $\mathrm{f}=$ Detected frequency in $\mathrm{Hz} ; \mathrm{R}=$ Number of revolution $(\mathrm{RPM})$ and $\mathrm{E}=$ Number of targets.

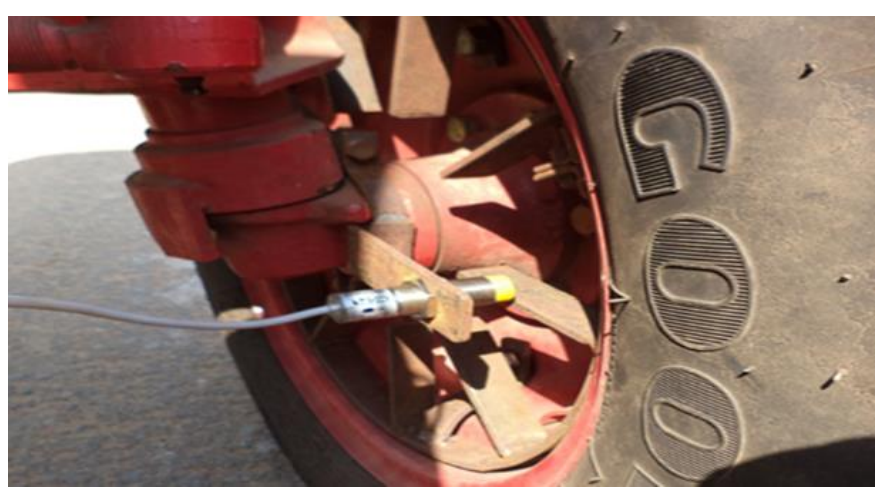

Fig 1: Components of Encoder

\section{Installation of encoders on the test tractor}

For RPM measurements, encoders were installed in both rear wheels and in one of the front wheels. The fixing was done in such a way that the metallic ring could rotate along with the movement of the axle. The outputs of three encoders were coupled to the designated pin of microcontroller for the slip computation. A test tractor equipped with encoders is shown in Figs 2 and 3 and overall view of installed encoder in Fig. 4. The installation of encoder is very easy and can easily be shifted from one tractor to another without any difficulty as no modification is required either in tractor or in the encoder.

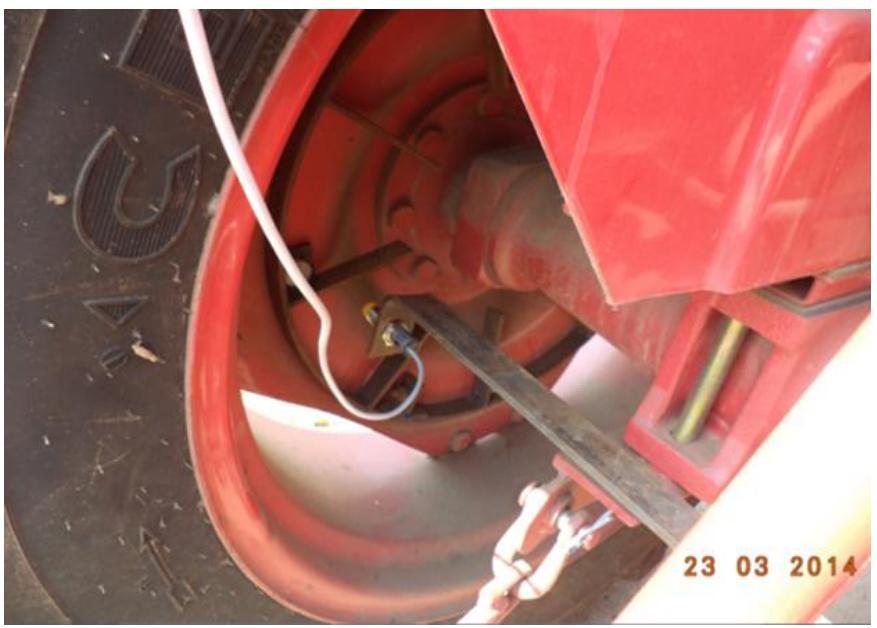

Fig 2: Mounted Encoders on Rear Wheel 


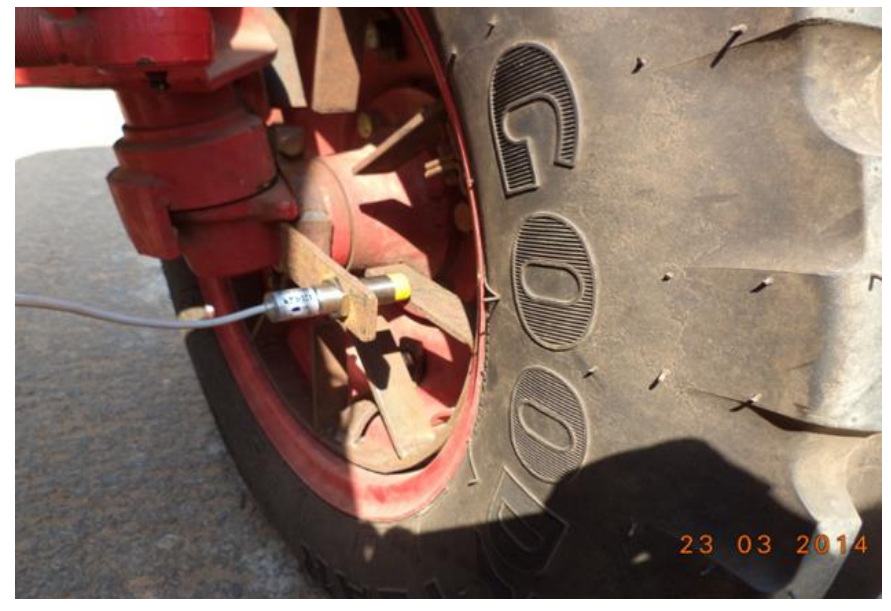

Fig 3: Mounted Encoders on front Wheel

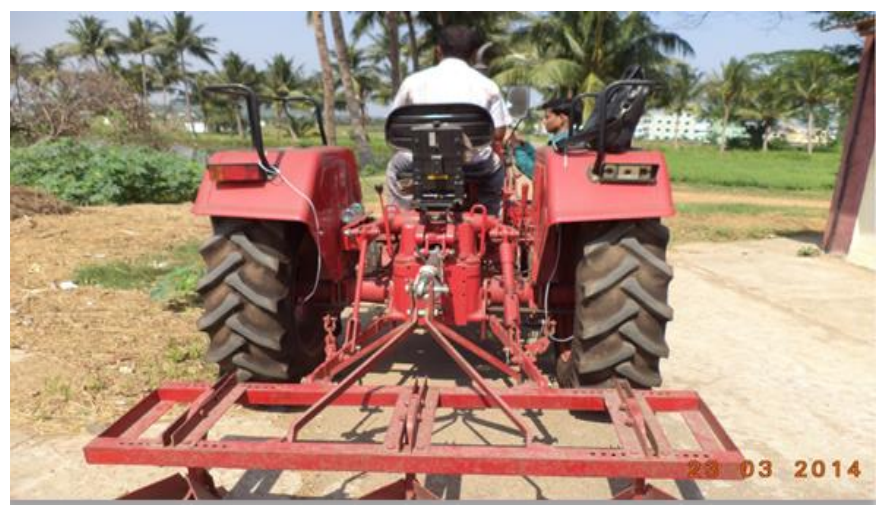

Fig 4: Overall view of Installed Encoders on a Tractor

\section{Microcontroller circuit development}

Microcontroller circuitry consists of the following major elements.

\section{Power supply}

Power supply circuit generates $+5 \mathrm{~V}$ power for the microcontroller. This power supply is derived from $12 \mathrm{~V}$ starter battery of the tractor. To achieve a stabilized output, the voltage regulator has been provided which generates constant $+5 \mathrm{~V}$ supply with maximum 1 ampere current. There is a protection against thermal overload and short circuit

\section{Signal rectification process}

Each encoder feeds signal to the concerned pin of the microcontroller. Output signal of the encoders are initially processed by signal conditioner circuit before the same is fed to the microcontroller circuits. The signal conditioner contains four nos. of 2 Input NAND gates. The input to the Signal conditioner is standard TTL input and it provides standard TTL output. These gates transform slow changing input signals into sharp and jitter free output to microcontroller for easy detection and counting. The magnetic pick up sensor provides slow changing output but the microcontroller need sharp transition signal for computation purpose. A Schmitt trigger circuit is used to provide positive feedback to change this slow transition to fast transitions which can easily be recognized by the microcontroller as shown in Fig. 5

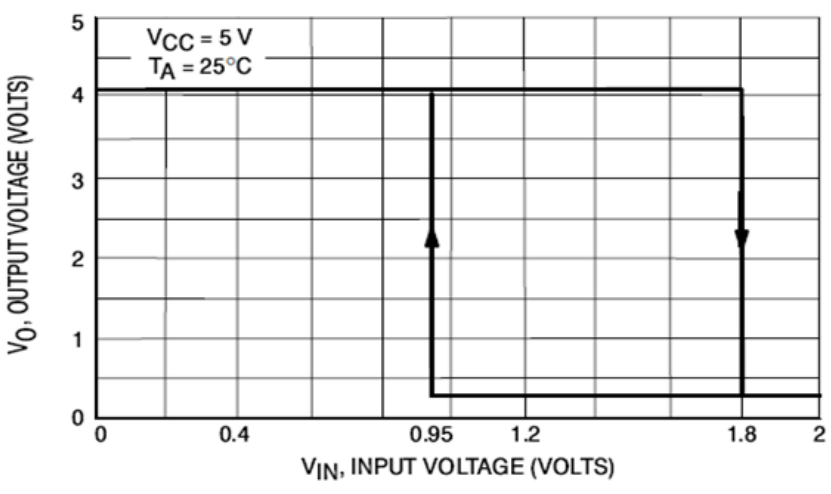

Fig 5: $\mathrm{V}_{\text {IN }}$ versus $\mathrm{V}$ out Transfer Function

\section{Output Display}

The data display is done in an LCD assembly. It is connected with the microcontroller by using 4 pins interconnections. The 4 pin interface is used for making the microcontroller capable of future up gradation and also interfacing other components. The CD 4094BC contain 8 bit SR and a 3 STATE 8-bit latch. Serial shifting of data is carried out through the shift register on positive clock transition. The output is cascaded through number of stages. Data latching is done on negative edges of the strobe input. Data propagates when the strobe through the latch to a 3 states o/p goes HIGH. These output gates are enabled when $\mathrm{o} / \mathrm{p}$ enable is kept high. When the strobe is high, data propagates through the latch to 3 STATE output gates.

\section{Communication}

The communication system was designed with RS232 serial port. An application was used with the help of hyper terminal to display the data. The microcontroller is interfaced with a $1 \mathrm{C}$ MAX 232. It is a driver/receiver which converts $+5 \mathrm{~V}$ CMOS/TTL to EIA 232. The serial port transfers the data by the serial port with a fixed baud rate. The pin 2 is used for receiving while the pin 3 is used for transmitting. Data is captured in the hyper terminal and stored in text format for the analysis.

\section{Microcontroller (P89V51RD2)}

The Phillip's P89V51RD2 microcontroller operate in X2 mode applications. The system can be designed to run in conventional clock rate of normally 12 clocks per cycle. Whereas, in X2 modes only 6 clocks are selected. As the clock frequency is reduced by $50 \%$, the EMI also gets reduced. The flash program supports both serial and parallel programs. The ISP (In System Programming) offer gang programs at high speed by which the cost of the programming is reduced. ISP enables for reprogramming at the end of the product under software control. A wide range of up-gradation is possible due to the versatility of the application firmware.

\section{Computation of slip in microcontroller}

All encoders are given power supply separately by the developed slip meter circuit. The output from the encoders was fed to the microcontroller separately. Before the signal reached at the microcontroller, it was processed by a NAND $747 \mathrm{~S} 132$ circuitry. The processed data is transferred to the 
timer pin of Phillips P89V51RD2 microcontroller. A software program is written in $\mathrm{C}^{++}$for the microcontroller to facilitate computation of speeds and slip.

Microcontroller computes the RPM and Slip of the wheels and the results are displayed instantly on the LCD screen provided in front panel of the slip meter. The identifications of RPMs of rear wheel1, rear wheel 2 and front wheel are represented by Er1, Er2 and Ef respectively. The under mentioned equations have been considered for the calculations of actual and theoretical velocity and slip which is derived from the signal generated by the encoders. The block schematic diagram of the developed slip meter and algorithm for the calculation is presented in Fig 6 . Calculations of rear and front wheel revolution per second (RPS)

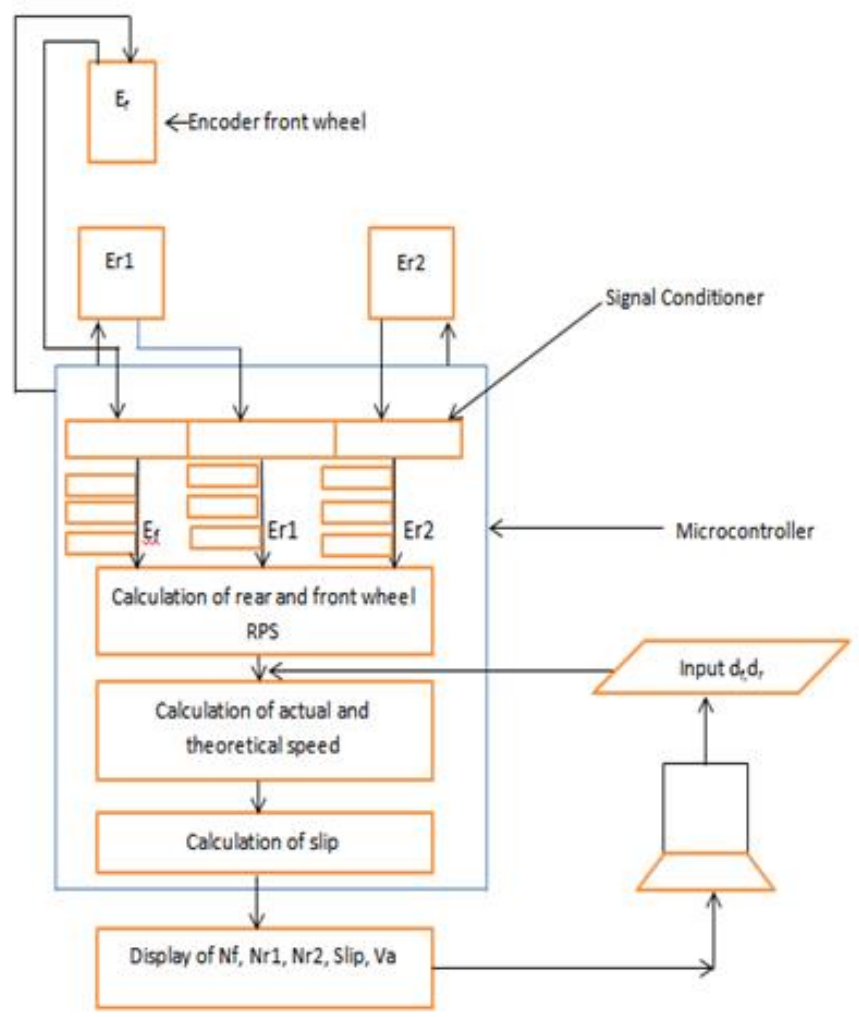

Fig 6: Layout of the Developed Slip-meter

$\mathrm{Nf}=\frac{\mathrm{Ef} \times 20}{360 \times \mathrm{T}}, \mathrm{Nr} 1=\frac{\mathrm{Er} 1 \times 20}{360 \times \mathrm{T}}, \mathrm{Nr} 2=\frac{\mathrm{Er} 2 \times 20}{360 \times \mathrm{T}}$

Calculation of actual and theoretical speed

$\mathrm{Va}=\mathrm{df} \times \mathrm{Nf}, \mathrm{Vt}=\mathrm{dr} \times \frac{\mathrm{Nr} 1+\mathrm{Nr} 2}{2}$. Calculation of wheel slip, $\mathrm{S}=\left(1-\frac{\mathrm{Va}}{\mathrm{Vt}}\right) \times 100$

where, $E_{\mathrm{f}}=$ number of pulses from front wheel encoder in $\mathrm{T}$ sec; $\mathrm{Er}_{1}{ }^{=}$no. of pulses from right real wheel encoder in $\mathrm{T} \mathrm{sec}$; $\mathrm{Er}_{2}=$ no of pulses from left rear wheel encoder in $\mathrm{T}$ sec; $\mathrm{N}_{\mathrm{f}}=$ revolution per second of front wheel; $\mathrm{N}_{\mathrm{r} 1}=$ revolution per second of right rear wheel; $\mathrm{N}_{\mathrm{r} 2}=$ revolution per second of left rear wheel; $\mathrm{T}=$ refreshment time i.e $1.5 \mathrm{~s} ; \mathrm{V}_{\mathrm{a}}=$ actual velocity, $\mathrm{m} / \mathrm{s} ; \mathrm{V}_{\mathrm{t}}=$ theoretical velocity, $\mathrm{m} / \mathrm{s} ; \mathrm{d}_{\mathrm{f}}=$ distance covered in one revolution by front wheel, $\mathrm{m} ; \mathrm{d}_{\mathrm{r}}=$ distance covered in one revolution by rear wheel, $\mathrm{m}$; and $\mathrm{S}=$ wheel slip, \%

The RPM of the two rear wheels are sensed by the Encoder no 1 and Encoder no 2, whereas, the Encoder no 3 sense the rotations of front wheel. Finally, the slip meter provides the digital display of the RPM of front/rear wheels and wheel slip on LCD screen. Fig. 8 shows the field trials of slip meter fitted with the tractor

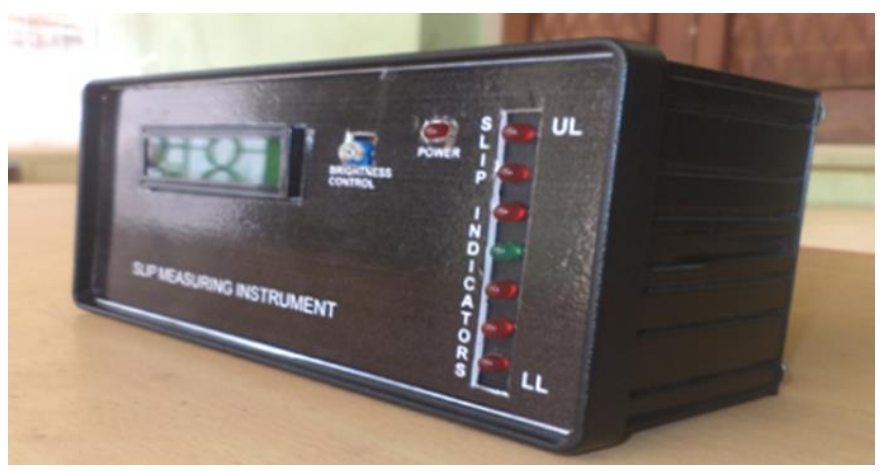

Fig 7: Outer and inner view of the developed Slip meter

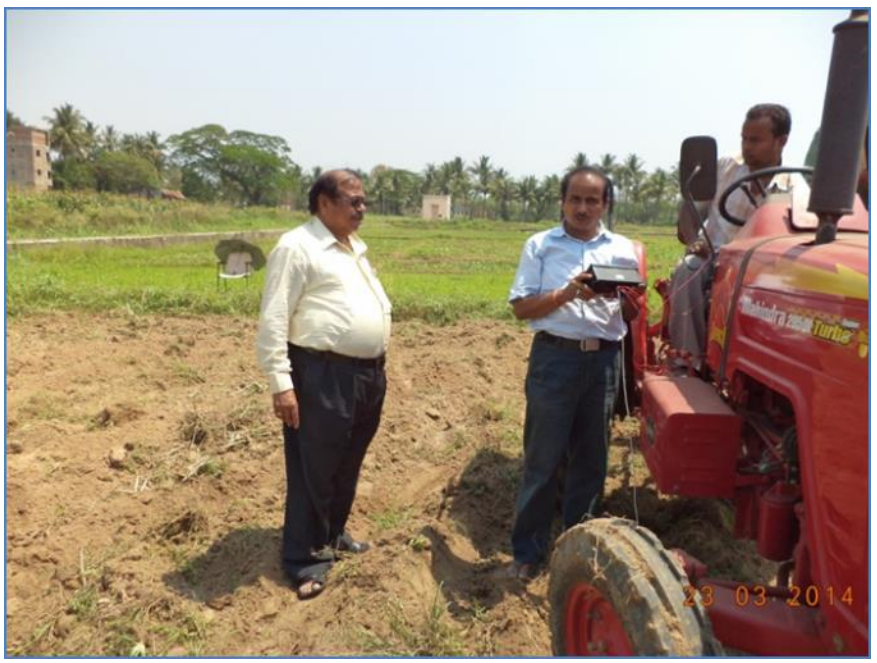

Fig 8: Field trials of slip meter fitted with the tractor

\section{Results and Conclusion}

The results of various tests conducted in laboratory and fields are presented in this section. Experiments were conducted to evaluate the performance of the developed slip meter in the laboratory and actual field condition and the following results were observed.

1. A digital slip meter was developed for $2 \mathrm{WD}$ tractors for online measurement of the wheel slip in actual field condition. The measuring efficiency and maximum error of the developed slip meter were found above $99 \%$ and 0 . $02 \%$ respectively

2. A radar sensing technique was employed to check and validate the actual speed of the tractor. There was no significant effect of front wheel skid in actual speed measurement technique. Maximum efficiency was better than $99 \%$, accuracy was $0.49 \%$

3. Since the slip meter is a compatible universal device for all make and models of 2WD tractors, the slip control method can be implemented in any make and model of $2 \mathrm{WD}$ tractors by uploading their wheel radius and the optimum slip range of the soil under operations to get the maximum tractive efficiency.

4. The tractors with slip control process remained operational for $70-80 \%$ of the time in the desired range of slip whereas, with the existing DCS, it could be operated with similar setting $\pm 2.5 \%$ draft and similar field conditions for $42-44 \%$ of time.

5. As compared to the existing draft control system the developed slip control system showed significant 
improvement in fuel economy i.e. $25-32 \%$ in ploughing $15-32 \%$ in harrowing and $6-25 \%$ in tilling and the improvement in field capacity was from $15-20 \%$ in ploughing $9-37 \%$ in harrowing and $10-24 \%$ in tilling as compared to DCS.

In agricultural sector, fuel consumption is a major concern as $35 \%$ of the operational cost is attributed towards the cost of fuel. Fuel efficiency is maximized by optimising the tractive efficiency which can be achieved by matching the tractor with implement size and load for a given tractor. In a practical situation, it is observed that for achieving the maximum efficiency, slip control system is highly preferable as compared to draft control system. This necessitates a control system which will continuously measure the slip to help the driver for managing wheel slip within a given range under varying soil and field conditions. The developed system is a simple one and needs no modification in the wheels of the tractor. It is therefore necessitated that the all tractor manufacturing company need to adopt the device for better fuel economy in the operation of tractor as presently tractor population is increasing at a faster rate in our country.

\section{References}

1. Tiwari VK, Pandey KP, Pranav PK. A Review on Traction Prediction Equations, Journal of Tenamechanics. 2009; 47(5):191-199.

2. Sharma AK, Pandey KP. Traction Data Analysis in Reference to a Unique Zero Condition. Journal of Terramechanics. 1998; 35:179-188.

3. Raheman H, Jha SK. Wheels Slip Measurement in 2WD Tractor. Journal of Terramechanics. 2007; 44:89-94.

4. Pranav PK, Pandey KP. Computer Simulation of Ballast Management for Agricultural Tractors. Journal of Terramechanics. 2008; 45:185-192

5. Kumar R, Pandey KP. A Program in Visual Basic for Predicting Haulage and Field Performance of 2WD Tractors. Computer and Electronics in Agriculture. 2009; 67:18-26.

6. Behera LN. Tractor Slip Measurement by Microprocessor Kit, Unpublished M. Tech. Thesis. Agricultural and Food Engineering Department, IIT Kharagpur, India, 1989. 